\title{
Systemic Administration of Ciliary Neurotrophic Factor Induces Cachexia in Rodents
}

\author{
Jeffrey T. Henderson, ${ }^{\star}$ Nadine A. Seniuk, ${ }^{\star}$ Peter M. Richardson, ${ }^{\star}$ Jack Gauldie, ${ }^{5}$ and John C. Roder \\ *Samuel Lunenfeld Research Institute, Division of Neurobiology and Molecular Immunology, Mount Sinai Hospital, Toronto, \\ Ontario M5G-1X5; ' Department of Neurosurgery, Montreal General Hospital, Montreal, Quebec H3G-1A4; and \\ ${ }^{\S}$ Department of Pathology, McMaster University, Hamilton, Ontario L8N-3Z5, Canada
}

\begin{abstract}
Ciliary neurotrophic factor (CNTF) has previously been shown to promote the survival of several classes of neurons and glial. We report here that in addition to its effects on the nervous system, CNTF can induce potent effects in extra-neural tissues. Implantation of $\mathbf{C 6}$ glioma cells engineered to secrete CNTF either subcutaneously or into the peritoneal cavity of adult mice, or systemic injections of purified rat or human recombinant CNTF, resulted in a rapid syndrome of weight loss resulting in death over a period of 7-10 d. This weight loss could not be explained by a reduction in food intake and involved losses of both fat and skeletal muscle. CNTF also induced the synthesis of acute phase proteins such as haptoglobin. Implantation of C6 lines expressing a nonsecreted form of CNTF, or the parental C6 line itself, did not result in wasting effects. Analysis of this CNTF-induced wasting indicates similarities with the previously described cachectins, tumor necrosis factor, interleukin 6 , and leukemia inhibitory factor, but does not involve the induction of these cytokines. (J. Clin. Invest. 1994. 93:26322638.) Key words: wasting • cytokine $\bullet$ acute phase $\bullet$ mice $\bullet$ drinking
\end{abstract}

\section{Introduction}

Ciliary neurotrophic factor $(\mathrm{CNTF})^{1}$ is a $23-\mathrm{kD}$ cytoplasmic protein which is expressed in both the peripheral and central nervous system beginning in the late embryonic period (1). This protein has been shown to exhibit a variety of activities, affecting both the differentiation and survival of neural and glial cells (2-4). CNTF shares important structural and functional properties with the cytokines interleukin 6 , leukemia inhibitory factor/cholinergic determining factor (LIF/CDF), interleukin 11, and oncostatin M (5). For this reason, CNTF is often referred to as a "neurokine" (6).

CNTF is thought to mediate its effects through a tri-partite receptor complex composed of $\mathrm{gp} 130$, the LIF $\beta$ receptor (LIFR $\beta)$, and a CNTF-specific $\alpha$ receptor $($ CNTFR $\alpha)(7,8)$.

Address correspondence to Dr. Jeffrey T. Henderson, Room 860, Mount Sinai Hospital, 600 University Avenue, Toronto, 0N M5G1X5, Canada.

Received for publication 5 November 1993 and in revised form 31 January 1994

1. Abbreviations used in this paper: CDM, cell dilution medium; CNTF, ciliary neurotrophic factor; GFAP, glial fibrillary acidic protein; LBM, lean body mass; LIF, leukemia inhibitory factor; $\mathrm{s}$ and ns, secretory and nonsecretory, respectively.

J. Clin. Invest.

(C) The American Society for Clinical Investigation, Inc.

$0021-9738 / 94 / 06 / 2632 / 07 \quad \$ 2.00$

Volume 93, June 1994, 2632-2638
Whereas gp130 and LIFR $\beta$ are expressed in a broad range of tissues, expression of the $\alpha$ receptor is much more restricted, being confined primarily (although not exclusively) to neural cells. Functional receptors for CNTF may however exist at extraneural sites, given the distribution of gp 130 and LIFR $\beta$, and the presence of CNTFR $\alpha$ in skeletal muscle and liver $(8,9)$. In addition, cleavage of the CNTFR $\alpha$ glycosyl-phosphatidyl inositol linkage to produce a soluble isoform may further extend the range of CNTF responsive tissues. Such receptor "shedding" has, in fact, been observed from skeletal muscle after nerve injury (9).

Given the potential for functional CNTF receptors at extraneural sites, we decided to examined the effects of systemic administration of CNTF. CNTF exhibits a short biological half-life in vivo (10); thus making it difficult to maintain stable levels of this agent systemically. We therefore developed stable cell lines which expressed either a secreted (CNTF-s) or nonsecreted (CNTF-ns) form of rat CNTF. Implantation of a known quantity of these cells produced a relatively stable amount of active neurotrophic agent whose effects were determined. We observe that mice receiving CNTF-s but not CNTF-ns cells exhibit a loss of body mass which is much more extensive than that reported for previously described cachectins. These data also demonstrate that the CNS effects of CNTF represent only one segment of its biological activities.

\section{Methods}

Construction and expression of CNTF-producing cells. For both secretory and nonsecretory CNTF expression constructs, the 600-bp fulllength rat CNTF cDNA was placed under the control of the 2.56-kb glial fibrillary acidic protein (GFAP) promoter (kindly provided by $\mathrm{K}$. Mikoshiba, Osaka, Japan). The CNTF secretion construct contained an additional 80-bp fragment that encoded the human growth hormone signal sequence, which was fused in-frame to the start of the CNTF cDNA. Stable cell lines were produced by lipofectin-mediated transfection as previously described (11). Rat C6 glioma cells (ATCC CCL No 107) were co-transfected in a 10:1 ratio with one of two CNTF expression constructs and the selectable marker GEO (provided by Philip Soriano, Baylor University, Houston, TX), which encodes a fusion protein of neomycin and $\beta$-galactosidase. Single cell clones were isolated and expanded under antibiotic selection $(1 \mathrm{mo})$. The resulting cell lines expressed a stable phenotype of $\mathrm{Neo}^{+}, \mathrm{Lac}^{+}, \mathrm{CNTF}^{+}$in continuous culture. Southern analysis of these lines demonstrated the expected pattern of hybridization.

Animals. Experiments were performed using age-matched, sexmatched litters of 9-wk-old CD1 mice or 8-wk-old C57BL/6J mice. Starting weights for CD1 animals were $29 \pm 2 \mathrm{~g}$. Initial weights for C57BL/6J mice were $20 \pm 1.3 \mathrm{~g}$. Litters of postnatal day 4 SpragueDawley rat pups were used to monitor the effects of CNTF in the early postnatal period. All animals received food and water ad lib., were weighed daily, and were raised under identical conditions in the same room of our animal facility. Animals were routinely killed when their 
total body mass reached $65 \%$ of its original value. All experimental protocols were approved and conformed to Animal Colony Care guidelines.

Implantation of $\mathrm{C} 6$ cells. Rat $\mathrm{C} 6$ glioma cells were harvested from culture. 1 million viable cells were then injected either subcutaneously, or into the lower left peritoneal cavity of each animal (using a 23-gauge needle), typically at a concentration of $5.0 \times 10^{6}$ cells $/ \mathrm{ml}$.

Western analyses. Samples were resolved by on a $15 \%$ polyacrylamide gel by SDS-PAGE as previously described (11). After separation, proteins were transferred to nitrocellulose membranes (Schleicher \& Schull Inc., Keene, NH; BA85) via electrophoretic transfer as described (11). After blocking with casein, affinity-purified CNTF anti-peptide antibody (12) was then added for a period of $4-12 \mathrm{~h}$ at $25^{\circ} \mathrm{C}$ with mild agitation. After removal of the primary antibody, the secondary antibody (Promega Corp., Madison, WI; alkaline phosphatase anti-rabbit) was then added at a dilution of 1:1,500 in wash buffer, and incubated for $2 \mathrm{~h}$ at room temperature with mild agitation. Blots were developed for $20 \mathrm{~min}$, using a bromochloroindolyl phosphate/nitroblue tetrazolium substrate $(0.0165 \%$ and $0.033 \%$, respectively), and reactions were stopped by rinsing blots in PBS, pH 8.0, containing 20 mM EDTA.

Immunohistochemistry. Cultures of CNTF-producing cells and peritoneal sections from animals receiving CNTF cell implants were fixed in methanol $\left(-20^{\circ} \mathrm{C}\right)$ or $4 \%$ paraformaldehyde, respectively. Samples were blocked with $10 \%$ normal goat serum for $30 \mathrm{~min}$, and incubated with affinity-purified anti-CNTF antibody (1:500 dilution of a 5 $\mu \mathrm{g} / \mathrm{ml}$ stock, in $1 \%$ normal goat serum $/ 2 \%$ normal mouse serum $/ 0.1 \mathrm{M}$ PBS) overnight at $4^{\circ} \mathrm{C}$. Samples were subsequently washed and incubated with biotinylated IgG (1:200 dilution of goat anti-rabbit or horse anti-mouse) for $40 \mathrm{~min}$ at room temperature, washed, and then incubated with avidin-horseradish peroxidase (1:200 dilution of standard Elite kit; Vector Labs, Burlingame, CA) for $30 \mathrm{~min}$. Samples were then reacted with $1 \mathrm{mg} / \mathrm{ml}$ diaminobenzidene (Sigma Chemical Co., St. Louis, MO) $0.02 \% \mathrm{vol} / \mathrm{vol}$ hydrogen peroxide to make visible the antigen-antibody complexes.

Cytokine and haptoglobin assays. Sera were obtained by standard methods (13) and analyzed for the cytokines indicated below. CNTF activity was determined using a chick ciliary ganglion survival assay as described previously (14). In all cases, addition of anti-CNTF antibody was found to inhibit the trophic activity present, thus confirming its identity. TNF $\alpha$ was assessed by TNF $\alpha$-specific ELISA (Genzyme Corp., Cambridge, MA; no. 1509-00), according to the manufacturer's instructions. IL-6 activity was determined using a B9 plasmacytoma proliferation assay, as described previously (15). This cell line has been shown previously to be insensitive to CNTF, LIF, and TNF $\alpha$ (9). LIF trophic activity was determined using an M1 (ATCC TIB No. 192) proliferation assay, as described previously (16). This cell line been shown to respond to LIF and IL-6, but not CNTF or TNF $\alpha$ (9). Results for a given sample were thus compared with those obtained from the IL-6 assay for the identical sample. For IL-6 and LIF assays, colorimetric assessment of cell proliferation (MTT) was used in place of the described method. The lower limit of sensitivity for each assay was as follows: TNF $\alpha 80 \mathrm{pg} / \mathrm{ml}$, IL-6 $10 \mathrm{pg} / \mathrm{ml}$, LIF $100 \mathrm{pg} / \mathrm{ml}$, and CNTF $100 \mathrm{pg} / \mathrm{ml}$

Haptoglobin concentrations were determined on triplicate dilutions of murine sera by rocket immunoelectrophoresis (13) against haptoglobin antisera. A set of standards of known concentration was run for each set.

Determination of lean body mass. 1 wk after i.p. implantation of cells, animals were killed and dissected to remove the skin, tail, and internal organs. Remaining body fat, if present, was also removed. The weight of the remaining carcass (primarily the skeleton and skeletal muscle) was then determined and reported as "lean body weight."

Measurement of coordination and grip strength. Coordination was examined by determining the time period animals could remain on a $1 / 4$-in. dowel, rotating at $1 \mathrm{rps}$, suspended $4 \mathrm{~cm}$ from the cage floor. Grip strength was determined by the time animals could continue gripping a wooden dowel with their forelimbs, suspended so that animals were 2 $\mathrm{cm}$ above the cage floor.
$\beta$-Galactosidase staining. Sections of peritoneum and underlying

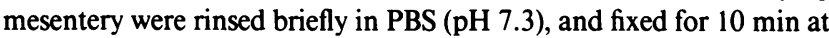
room temperature in $0.2 \%$ paraformaldehyde. Sections were then washed in $2 \mathrm{mM} \mathrm{MgCl}, 0.01 \%$ sodium deoxycholate, $0.02 \%$ Nonidet-

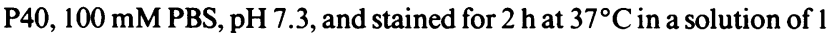
$\mathrm{mg} / \mathrm{ml} \mathrm{X-gal} \mathrm{(Bethesda} \mathrm{Research} \mathrm{Laboratories,} \mathrm{Gaithersburg,} \mathrm{MD),} \mathrm{4 \%}$ dimethyl formamide, $5 \mathrm{mM}$ potassium ferrocyanide, and $5 \mathrm{mM}$ postassium ferricyanide, dissolved in wash buffer.

Statistical analysis. Data are displayed \pm SEM. Differences between groups were analyzed using Student's $t$ test. Groups were determined to differ significantly provided $P<0.05$. Unless otherwise noted, data represent the results obtained from $n=20$ animals per treatment group.

\section{Results}

In order to produce CNTF from rat $\mathrm{C} 6$ glioma cells, gene cassettes encoding either a secretory or nonsecretory form of rat CNTF were placed under the control of the GFAP promoter, as shown in Fig. $1 \mathrm{~A}$. Western analyses demonstrate that both the CNTF-s and CNTF-ns cell lines, but not the parental C6 line, exhibit a protein doublet of $\sim 23 \mathrm{kD}$ with a minor species present at $40 \mathrm{kD}$ (Fig. $1 \mathrm{~B}$ ), as previously described for purified CNTF $(14,17)$. Densitometric scans of Western blots from several independent cultures indicate that the CNTF-ns line produces $\sim 6 \mu \mathrm{g}$ of $\mathrm{CNTF} / 1 \times 10^{6}$ cells per $24 \mathrm{~h}$ in serum-free media, with $97 \%$ of the protein present in the cytoplasmic fraction. The secretory CNTF line produces $\sim 8.2 \mu \mathrm{g}$ of CNTF/1 $\times 10^{6}$ cells per $24 \mathrm{~h}$ in serum-free media, with $86 \%$ of this activity present in the culture medium. Bioassays of culture medium from the CNTF secretory lines indicate that the trophic activity present is comparable on a molar basis to that observed with the nonsecretory line and purified rat sciatic nerve CNTF in dorsal root (rat) and ciliary ganglia (chick) cultures (data not shown). Thus these CNTF-expressing cell lines produce biologically active CNTF which is targeted to the appropriate cellular compartment. Immunohistochemical staining of these cells (Fig. $1 C$ ) showed intense staining in the perinuclear region, at the Golgi apparatus, consistent with the localization observed for other secreted proteins.

Implantation and effects of CNTF-expressing cells. 9-wkold CD1 mice receiving i.p. implants of $1 \times 10^{6}$ cells were divided into four basic groups. Animals received either: $(a)$ cell dilution medium alone (CDM), $(b)$ the parental rat $\mathrm{C} 6$ cell line (C6), (c) the CNTF-ns cell line, or (d) the CNTF-s cell line. Implantation of $\mathrm{C} 6$ glioma cells within the peritoneal cavity resulted in the continued growth and proliferation of these cells, particularly along collagenous mesenteries. CNTF-s and CNTF-ns cells appeared to proliferate at similar rates, with the nonsecretory cells exhibiting a slightly higher mitotic index. Since these cells express $\beta$-galactosidase, they could be unequivocally identified from the surrounding tissue (Fig. $1 \mathrm{D}$ ).

Implantation of nonsecretory and secretory CNTF-expressing cells had vastly different effects on the recipient animals. Little change in body mass was observed for animal injected with the cell dilution media, whereas the C6 and CNTFns-injected animals showed small increases due to the retention of ascites fluid (Fig. $2 A$ ). Animals receiving CNTF secretory cells however, exhibited a dramatic decrease in body weight, which began immediately and continued until the time of killing ( $65 \%$ of original body mass). This loss of body mass proceeded despite continued food intake (see below). A postmortem analysis of these animals at postimplantation day 7 
A

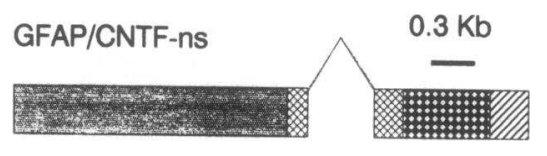

GFAP/CNTF-s

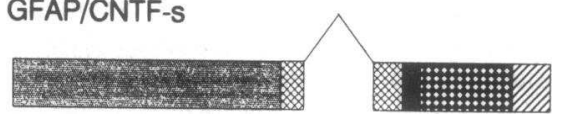

B

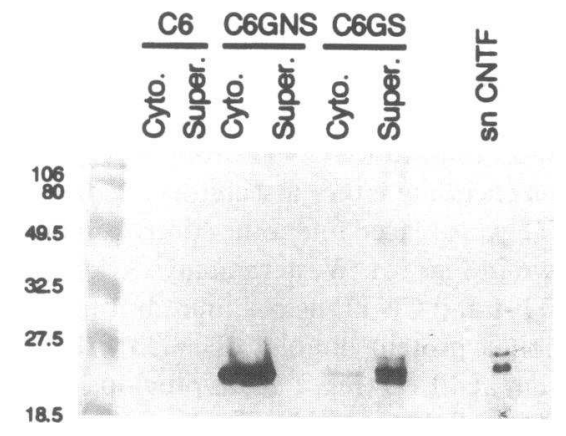

C

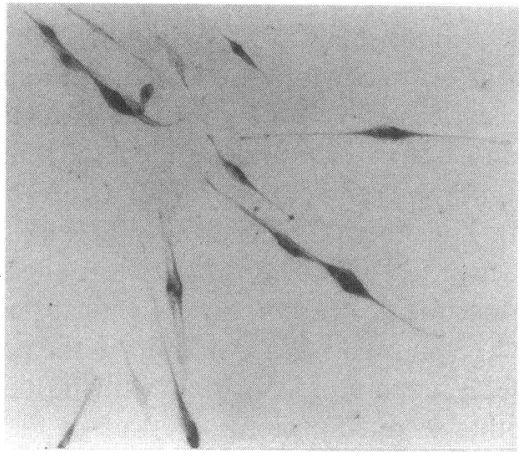

D

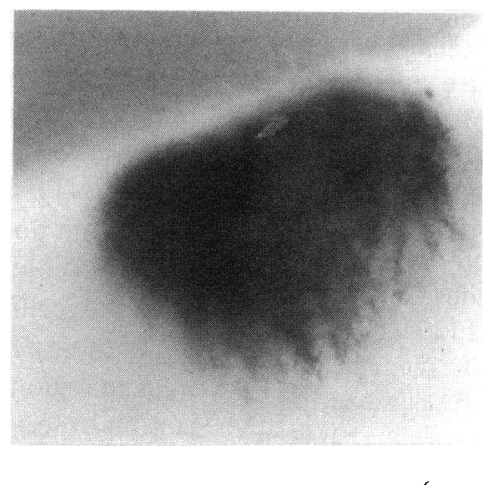

Figure 1. Production of CNTF-expressing cell lines. (A) Schematic of CNTF expression vectors. ( $\square$ ) GFAP promoter; ( $\otimes$ ) modified globin intron b; ( $\square$ ) human growth hormone signal sequence; (田) full-length CNTF cDNA; ( $\square$ ) SV40 poly $A$. (B) Western blot of cell extracts from CNTF-expressing cells. Each lane represents the extract from 60,000 cells over a period of $24 \mathrm{~h}$ grown in serum-free media. Primary antisera consisted of an affinity purified antibody raised to a rat CNTF peptide (12). C6, rat C6 glioma cells; C6GNS, CNTF nonsecretory cell line; C6GS, CNTF secretory cell line; cyto., cytoplasmic cell extract; super., cell-free supernatant; sn CNTF -rat sciatic nerve CNTF. A set of pre-labeled MW standards (Bio Rad) were run with the sample set. Note that the parental rat $\mathrm{C} 6$ line does express minute quantities of CNTF, which can ge detected at sufficiently high protein concentrations. $(C)$ Staining of CNTF secretory C6 cells for rat CNTF. (D) Lac-Z staining of CNTF-s cells within a peritoneal mesentery, $3 \mathrm{~d}$ postimplantation. revealed a virtual elimination of all stores of body fat, including subcutaneous and brown fat. Removal of CNTF-secreting cells (s.c implants) before day 6 resulted in a reversion of these effects (data not shown). Similar results were obtained using subcutaneous (s.c.) implants, or with 8-wk-old C57BL/6J mice (i.p. and s.c. sites). CNTF-s-treated animals also exhibited a ruffled appearance, hunched posture, and an abnormal gait, which were observable by day 4 . However, no reductions in coordination or grip strength were observed before day 6 . Histological examination of these animals revealed several anomalies which were specific to the CNTF-s group, including thymic atrophy, gall bladder enlargement, and elevations in red blood cell content within bone marrow (Henderson, J. T., N. A. Seniuk, J. Gauldie, B. Mullen, and J. C. Roder, manuscript submitted for publication). Analysis of peripheral blood lymphocytes showed no significant numerical differences between any of the groups from 0 to $7 \mathrm{~d}$ (data not shown).

To determine whether the effects observed with CNTF-secreting cells in mice represented a species-specific phenomenon, Sprague-Dawley rat pups were implanted with $1 \times 10^{6}$ CNTF secretory or nonsecretory cells at postnatal day 4. As shown in Fig. $2 B$, animals which received CNTF-s cells exhibited a dramatic retardation in growth which was not observed in the CNTF-ns group. Postmortem analysis of these animals indicated findings similar to those found in mice.

The lean body mass (LBM) of mice in each treatment group at $7 \mathrm{~d}$ postimplantation is shown in Table $\mathrm{I}$. These data indicate that CNTF-s-treated animals have undergone a $20 \%$ reduction in muscle mass compared to the CDM, C6, and CNTF-ns groups (34.2\% vs. $42.7 \%$ ). Thus, in addition to fat, a dramatic loss of skeletal muscle protein (2.4-2.5 g per animal per week on average) has occurred during this time period. Examination of the LBM in terms of the final total body mass however, revealed that this value was higher in CNTF-s-treated animals relative to the other groups (Table I). This indicates that although LBM was reduced in CNTF-s-treated animals, other components of body mass were diminished at an even more rapid rate. The primary component in this effect appears to be adipose tissue. Among the internal organs, only the liver exhibited a significant decrease in mass in CNTF-s-treated animals compared to other treatment groups (Table I), which was primarily due to depletion of stored glycogen and lipids. 
A

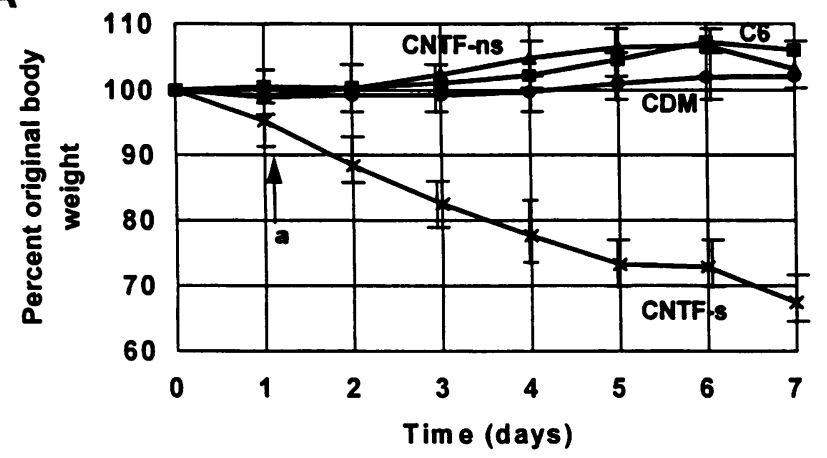

B

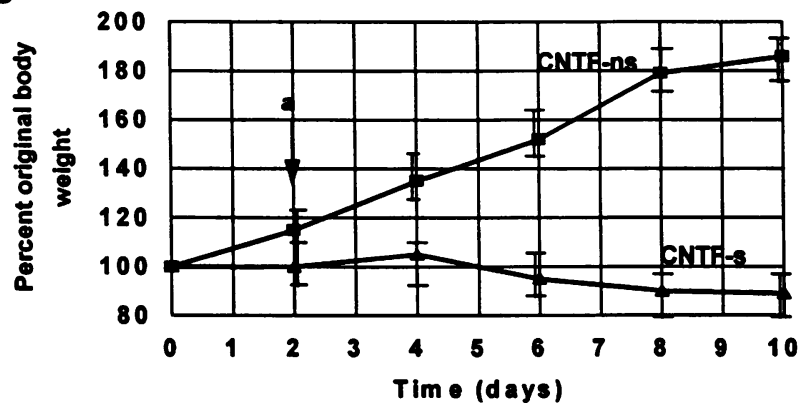

Figure 2. Change in total body weight in the presence of CNTF-expressing cells. Error bars indicate the maximum range observed at that time point for each group. Arrows indicate the time point at which CNTF-s treated animals differed significantly from other treatment groups $(a, P<0.05)$. $(A) 9$-wk-old litters of $C D 1$ mice weighing $29 \pm 2.0 \mathrm{~g}$ received $200 \mu \mathrm{l}$ i.p. injections of cell dilution medium $(\mathrm{CDM}, \bullet)$, or $1 \times 10^{6}$ cells of the following: rat C6 glioma cells (C6, a), CNTF-ns cells, (CNTF-ns, $\Delta$ ) or CNTF-s cells (CNTF-s, $X$ ). Animal weights were obtained at 24-h intervals and plotted as a percentage of their original body mass, $n=20$ animals per group. For experiments which required more than one litter of animals, age-matched litters from two sibling parents were combined such that offspring were evenly distributed among each of the experimental groups. $(B)$ Sprague/Dawley rat pup growth in the presence of CNTF-expressing cells. 4-d-old Sprague-Dawley pups received either $1 \times 10^{6} \mathrm{CNTF}$-s $(\triangle)$ or CNTF-ns ( $\square$ ) cells on day $0 ; n=4$ animals per group.
Elevations in acute phase proteins have been reported for animals treated with LIF, IL-6, and TNF (19), cytokines which induce a cachectic response. CNTF has also been reported to induce the synthesis of acute phase proteins in cultures of rat hepatocytes and in H-35 hepatoma cells in vitro $(20,21)$. We therefore examined samples of murine sera for levels of the acute-phase protein haptoglobin, to determine if CNTF produced similar effects in vivo.

As shown in Table I, a significant elevation in serum haptoglobin was observed in the CNTF-s-treated group. In order to rule out hepatic injury as a contributing factor in this effect, alanine transaminase levels were determined for each of the serum samples. Alanine transaminase levels for all samples were $<50 \mathrm{U} /$ liter, indicating an absence of significant tissue injury.

To determine if the wasting effects of CNTF were primarily due to anorexia (appetite suppression), food intake was measured for animals in each group. As shown in Table I, mice implanted with C6 or CNTF-ns cells did not exhibit a depression in food intake. Animals implanted with CNTF-s cells did show some decline in this value. This decrease however was insufficient to explain the profound degree of wasting which occurred over this time period.

Measurement of the fluid intake of animals in each group is also shown in Table I. These data indicate that CNTF-s-treated animals exhibit a substantial depression in fluid intake which is not observed in the other treatment groups. This CNTF-induced thirst suppression could be observed within $6 \mathrm{~h}$ after cell implantation, and was thus a relatively early consequence of CNTF action. This effect probably contributed to the subsequent loss of body mass in these animals (22). Note that CNTFns (but not C6)-treated animals also exhibited some depression in fluid intake. This may reflect a small amount of CNTF "leakage" from these cells (see Table II).

In order to determine the "dose response" of CNTF with respect to its wasting effects, animals were implanted with varying numbers of CNTF-secreting cells. These results, shown in Fig. $3 \mathrm{~A}$, demonstrate that while implantation of $1 \times 10^{5}$ cells did not result in overt cachexia, implantation of $0.5 \times 10^{6}$ cells did lead to detectable wasting effects, while implantation of $1 \times$ $10^{6}$ cells approached the saturating quantity for this effects in CD1 mice.

Table I. Metabolic Effects of CNTF

\begin{tabular}{lrrrr}
\hline & \multicolumn{4}{c}{ Treatment group } \\
\cline { 2 - 5 } \multicolumn{1}{c}{ Metabolic effect } & \multicolumn{1}{c}{ CDM } & \multicolumn{1}{c}{ C6 } & \multicolumn{1}{c}{ CNTF-ns } & CNTF-s \\
\hline LBM/init. TBM (\%) & $42.7 \pm 0.28$ & $43.5 \pm 0.34$ & $42.4 \pm 0.23$ & $34.2 \pm 0.30^{\ddagger}$ \\
LBM/fin. TBM (\%) & $42.7 \pm 0.28$ & $41.0 \pm 0.25$ & $41.5 \pm 0.27$ & $46.0 \pm 0.29^{\ddagger}$ \\
Liver/init. TBM (\%) & $4.5 \pm 0.07$ & $5.2 \pm 0.07$ & $4.9 \pm 0.07$ & $3.7 \pm 0.06^{\ddagger}$ \\
Liver/fin. TBM (\%) & $4.5 \pm 0.06$ & $4.6 \pm 0.08$ & $4.7 \pm 0.07$ & $5.0 \pm 0.06^{*}$ \\
Haptoglobin (mg/ml) & $0.32 \pm 0.02$ & $0.40 \pm 0.08$ & $0.56 \pm 0.04$ & $1.14 \pm 0.09^{\ddagger}$ \\
Food intake (\%) & $100 \pm 0.65$ & $125 \pm 1.00$ & $120 \pm 0.68$ & $82 \pm 0.74^{\ddagger}$ \\
Water intake (\%) & $100 \pm 0.56$ & $100 \pm 0.78$ & $80 \pm 0.65$ & $38 \pm 0.78$ \\
\end{tabular}

CD1 mice were implanted with $1 \times 10^{6}$ cells at day 0 and killed on day 7. LBM/init. TBM indicates the lean body (day 7) as a percentage of the total body mass (day 0 ). LBM/fin. TBM denotes lean body mass (day 7) as a percentage of the TBM (day 7). Data for liver are shown using similar nomenclature. For these studies, $n=20$ animals per group. Serum haptoglobin levels, obtained at day 7 , are reported in milligrams per milliliter; $n=6$ animals per group. Food and water intake for each group are shown as a percentage of the control (CDM) values. Data were obtained 0-4 days postimplantation, and were constant over this time period; $n=12$ animals per group. All values are shown \pm SEM. * Significant with respect to other groups at $P<0.05$; ${ }^{\ddagger}$ significant with respect to other groups at $P<0.01$. 
A

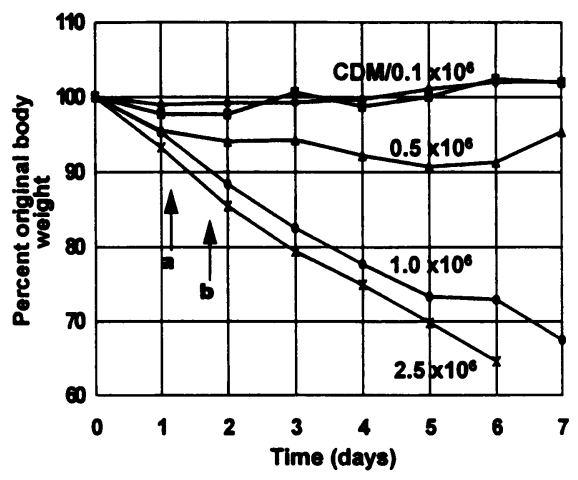

B

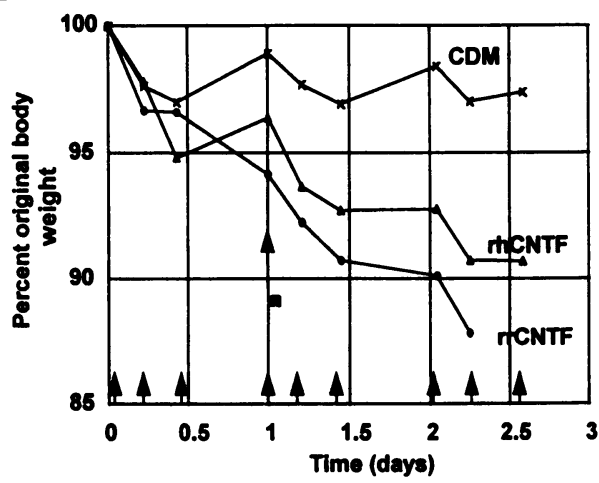

Figure 3. Wasting effects of secretory and recombinant CNTF. $(A)$ Effects of increasing numbers of CNTF secreting cells on body mass. Animals were injected with either cell dilution medium (CDM), or $0.1-2.5 \times 10^{6} \mathrm{CNTF}-\mathrm{s}$ cells i.p. and followed for $7 \mathrm{~d}$. For each of the given time points, the range of observed values did not exceed $\pm 1.3 \%$ of the indicated value. Arrow $a$ denotes the time at which 1.0/2.5 $\times 10^{6}$ CNTF-s groups differed significantly $(P<0.05)$ from CDM/0.1 $\times 10^{6} \mathrm{CNTF}$-s groups; arrow $b$ denotes time at which this group differed significantly from $0.5 \times 10^{6} \mathrm{CNTF}-\mathrm{s}$ group, $n=10$ animals per group. (B) CD1 mice injected with either CDM, rat ( $\Delta$ ) or human (•) CNTF. 2- $\mu \mathrm{g}$ doses of CNTF were administered in a solution of phosphate buffered saline ( $\mathrm{pH} 7.4$ ), $0.6 \%$ glucose, $100 \mu \mathrm{g} / \mathrm{ml}$ bovine serum albumin at the times indicated (arrowheads). Animals were weighed before receiving each i.p. injection. The range of observed values at each time point did not exceed $\pm 1.4 \%$ of the indicated value. Arrow $a$ denotes the time at which $\mathrm{rr} / \mathrm{rh}$ CNTF groups differed significantly $(P<0.05)$ from the CDM group; $n=4$ animals per group.

Effects of recombinant CNTF. In order to verify that the effects observed with secreted CNTF were not due to a serendipitous interaction via the altered amino terminus (which was fused to the human growth hormone signal sequence), adult CD1 mice were injected with recombinant rat ( $\mathrm{rCNTF}$ ) or human CNTF (rhCNTF). rrCNTF was produced from a bacterial expression plasmid (pGEX-2T) containing the complete rat CNTF cDNA fused to glutathione S-transferase (14). Thrombin cleavage of this product from a glutathione affinity matrix resulted in the addition of two amino acids (Gly, Ser) to the protein. This modification was distinct from that potentially present on CNTF-s, and has been shown not to perturb the biological properties of CNTF (14)-consistent with previous observations (23). The rhCNTF used in this study was identical to endogenous human CNTF (Scios, Nova, Moun- tain View, CA). $2 \mu \mathrm{g}$ of CNTF was injected i.p. three times per day, in order to compare the results obtained with those previously observed using LIF (24). These data (Fig. $3 \mathrm{~B}$ ) demonstrate that i.p. injection of rrCNTF or rhCNTF caused a decrease in body mass similar to that observed with $1 \times 10^{6}$ CNTF-s cells.

Further evidence that the CNTF secreted from C6 cells faithfully reproduced the biological activity of the nonsecreted (endogenous) CNTF protein was suggested from a small number of CNTF-ns animals which did not eliminate the implanted cells. These animals eventually developed proliferative CNTFns tumors (18-21 d) and were invariably sacrificed due to cachectic wasting. This was not observed in animals which developed proliferative $\mathrm{C} 6$ tumors (which were killed due to tumor proliferation). Thus both secreted and nonsecreted forms of CNTF could induce cachexia, which was not observed with the parental $\mathrm{C} 6$ tumor line alone. Taken together, these data indicate that the cachectic effects observed represent bona fide actions of the CNTF protein.

Analysis of cachectic cytokines. In order to determine whether the results obtained using CNTF reflected secondary induction of other known cachectins, samples of murine sera were assayed for various cytokines. As shown in Table II, detectable levels of TNF $\alpha(>80 \mathrm{pg} / \mathrm{ml})$, LIF $(>100 \mathrm{pg} / \mathrm{ml})$, or IL-6 $(>10 \mathrm{pg} / \mathrm{ml})$ were not observed in any group. The levels present (if any) were thus substantially below that required to induce even moderate cachectic wasting (24-26), suggesting that CNTF acts independently of these factors. Analysis of sera from animals receiving $1 \times 10^{6} \mathrm{CNTF}-\mathrm{s}$ cells revealed the presence of substantial quantities of ciliary ganglion trophic activity however $(10 \mathrm{ng} / \mathrm{ml})$. This trophic activity could be blocked by the addition of polyclonal rabbit CNTF antisera which inhibits CNTF activity in vitro (data not shown). Significant concentrations of CNTF were also observed in the sera of animals which received $1 \times 10^{6} \mathrm{CNTF}-\mathrm{ns}$ cells $7 \mathrm{~d}$ before $(\sim 3 \mathrm{ng} / \mathrm{ml})$. This value may be higher than expected owing to small amounts of immune-mediated cell lysis which may be occurring at this time.

\section{Discussion}

These data demonstrate that CNTF, when present systemically, induces a severe form of cachexia in both adult mice and neonatal rats. This effect was observed using implants of

Table II. Analysis of Murine Sera for Cachectic Cytokines

\begin{tabular}{lllll}
\hline $\begin{array}{c}\text { Cytokines } \\
(n g / m)\end{array}$ & TNF $\alpha$ & IL-6 & LIF & CNTF \\
\hline Group: & & & & \\
CDM & $<0.08$ & $<0.01$ & $<0.10$ & $<0.20$ \\
C6 & $<0.08$ & $<0.01$ & $<0.10$ & $<0.30$ \\
CNTF-ns & $<0.08$ & $<0.01$ & $<0.10$ & $\leq 3.0$ \\
CNTF-s & $<0.08$ & $<0.01$ & $<0.10$ & 10.0 \\
& & & & \\
\hline
\end{tabular}

Mice implanted with $1 \times 10^{6}$ cells at day 0 were killed on day 7 and dilutions of their sera analyzed for cytokines indicated. The lower limit of sensitivity for each assay is as follows: TNF $\alpha 80 \mathrm{pg} / \mathrm{ml}, \mathrm{IL}-6$ $10 \mathrm{pg} / \mathrm{ml}, \mathrm{LIF} 100 \mathrm{pg} / \mathrm{ml}, \mathrm{CNTF} 100 \mathrm{pg} / \mathrm{ml} ; n \geq 7$ individuals per group. 
CNTF-secreting cells, and was not found with nonsecreting CNTF-expressing cells or the parental C6 cell line. The degree of wasting was proportional to the number of CNTF-secreting cells implanted, and at saturating levels induced a $35 \%$ loss in body mass over a 1-wk time period. These effects could be reproduced by injection of recombinant rat or human CNTF protein, and appeared to be independent of TNF $\alpha$, IL-6, or LIF induction. The results indicate that CNTF is directly involved in the induction of cachexia, and defines a new biological activity for this protein.

Implantation of $1 \times 10^{5} \mathrm{CNTF}$-s cells did not lead to significant wasting, while implantation of $1 \times 10^{6}$ cells resulted in overt cachexia. These data suggest that a "threshold" of biologically active CNTF is required to bring about overt cachexia. This threshold is on the order of $100-200 \mathrm{ng} / \mathrm{g}$ weight per day for mice receiving i.p. injections of CNTF protein, and 5-10 $\mathrm{ng} / \mathrm{ml}$ serum for mice implanted with CNTF secretory cells. This latter concentration is similar to that used previously to determine the effects of CNTF on a variety of neural cells in vitro $(3,4,27)$. This indicates that the mechanism that mediates CNTF's cachectic response is of the same order of affinity as that mediating its survival properties in neural cells.

CNTF exhibits closest homology to IL-6 and LIF (5). Similarly, CNTFR $\alpha$ shares strongest homology with these cytokine receptors (6). The IL-6 receptor is composed of IL-6R $\alpha$ and gp 130, the LIF receptor is composed of gp 130 and LIFR $\beta$, and the CNTF receptor is composed of $\mathrm{gp} 130$, LIFR $\beta$ and CNTFR $\alpha(6,7,28,29)$. Thus, to a first approximation, IL-6, LIF and CNTF define a progressively restricted range of biological activities, largely due to spatial restriction of their receptor components $(6,8)$. An understanding of the biological activities which these factors share, such as cachexia and the induction of hepatic acute-phase proteins, may therefore best be determined through an examination of CNTF, which is more restricted in its sites of action. Analysis of CNTF-induced cachexia suggests that the liver, and perhaps skeletal muscle (sites of peripheral CNTFR $\alpha$ expression), are the primary sites mediating the induction of the cachectic state. While CNTF receptors are also expressed within the central nervous system $(8,9)$, interaction of CNTF directly with these sites does not appear to play a major role in the induction of cachexia (see below).

While CNTF, IL-6, and LIF all induce some degree of wasting, the strength of these effects appear to differ. Animals treated with CNTF appear to develop a more rapid and extensive form of wasting compared to these other cytokines (24, 25 ). While this may be due to variations in signal transduction at their respective cellular targets, it more probably reflects differences in the effective concentration of the cytokine at its sites of action. This may be influenced by factors such as biological half-life, number of receptor sites, subunit expression and receptor density.

Previously, high levels of CNTF protein $(1.5-7 \mu \mathrm{g} /$ day) have been introduced into the rat central nervous system via miniosmotic pumps at several intracranial sites $(30,31)$, without report of cachectic wasting. We have also failed observed cachexia in adult rats and mice receiving intracranial implants of CNTF-s cells. This suggest that the CNTF present within the central nervous system is inaccessible to those cellular targets which mediate its cachectic effects.

With regard to systemic administration, Sendtner et al. (10) have reported that implantation of embryonic stem cells producing a pre-pro nerve growth factor/murine CNTF product, can prevent motoneuron degeneration in pmn mice. Surprisingly, no mention of wasting is made for these animals, despite reporting CNTF serum levels of $500 \mathrm{U} / \mathrm{ml}$. The effects of introducing purified CNTF protein have thus far not been described for this mutant. While the primary defect of pmn is unknown, it is possible that it interferes with the pathway required for the mediation of CNTF's cachectic effects. In addition, this discrepancy may be due differences in the CNTF protein produced, as the pre-pro NGF region does not have a well-defined initiation or cleavage site.

CNTF induces catabolism of stored fat, skeletal muscle protein, and liver glycogen, and also depresses circulating concentrations of several intermediary metabolites (Henderson, J. T., N. A. Seniuk, J. Gauldie, B. Mullen, and J. C. Roder, manuscript submitted for publication); in a manner reminiscent of metabolic starvation. CNTF does not appear to be predominantly anoretic in nature, as CNTF-s animals exhibit insufficient reductions in food intake to explain the observed loss in body mass. CNTF did however cause a pronounced decrease in fluid intake in these animals. The rapid onset and degree of thirst suppression suggests that this is an early consequence of CNTF action, and no doubt contributes to the observed cachexia. The periventricular and supraoptic nuclei, are sites known to be involved in the regulation of thirst behavior in rodents (22). The blood-brain barrier proximal to this region contains fenestrations, suggesting a direct mechanism for CNTF in altering fluid intake. However, intracranial application of CNTF by ourselves and others argue against such a straightforward interaction. We believe that the majority of CNTF's cachectic effects result from the direct interaction of this neurokine with peripheral targets such as liver hepatocytes $(8,21)$. This in turn induces secondary mediators, such as the acute phase proteins which may interact with additional sites, altering metabolic function. Studies performed in vitro using hepatoma cell lines demonstrate that these cells express functional receptors for CNTF (and other cachectins), and that application of CNTF directly induces the synthesis of acute phase proteins $(21,32)$. Given the central regulatory role of the liver in intermediary metabolism, and its expression of a number of different cachectin receptors, it would appear to be a likely candidate as the prime mediator of cachectin action.

Much remains to be learned regarding the biochemical mechanism of cachectic wasting. It is interesting to note that many of the effects observed in CNTF-s-treated animals are similar to those seen in hyperthyroidism (33). In addition, several features of these animals, such as thymic atrophy, suggest alterations in their levels of glucocorticoids (Henderson, J. T., N. A. Seniuk, J. Gauldie, B. Mullen, and J. C. Roder, manuscript submitted for publication). Examination of the potential influence of CNTF on these metabolic hormones may provide a better understanding of its cachectic mechanism. With regard to triglyceride mobilization, it will be of interest to see if CNTF can alter the activity of catabolic enzymes such as lipoprotein lipase, which have been shown to be suppressed by LIF, and TNF $\alpha(34,35)$.

The data obtained indicate that CNTF exhibits major activities outside the nervous system proper in adult mice, demonstrating that the effects of CNTF on neural cells represents only a subset of the biological properties of this factor. These extraneural effects include the induction of rapid cachectic wasting, and the synthesis of the acute phase protein haptoglobin. In addition, animals receiving CNTF exhibited thymic atrophy, 
gall bladder enlargement, and elevations in red blood cell content as detailed elsewhere (Henderson, J. T., N. A. Seniuk, J. Gauldie, B. Mullen, and J. C. Roder, manuscript submitted for publication). CNTF mediated cachexia may provide a more specific model in which to examine this phenomenon in vivo. Understanding the mechanism of these CNTF-induced effects may be important, both in terms of defining the physiology of this factor, and in exploring its clinical applications for neural repair.

\section{Acknowledgments}

We would like to thank Colleen Clancey and Wanda Abramow-Newerly for animal handling and care, Monica L. Altares and Jane Ann Schroeder for technical expertise, SCIOS NOVA for the gift of human recombinant CNTF protein, and Katsuhiko Mikoshiba for providing the GFAP promoter.

This work is supported by the Canadian Network of Centers for Excellence on Neural Regeneration and Functional Recovery. Dr. Henderson in a Rick Hanson fellow; Dr. Seniuk is an N.C.E. fellow; and Dr. Roder is a Medical Research Council scientist.

\section{References}

1. Stockli, K. A., L. E. Lillien, M. Naher-Noe, G. Breitfeld, R. A. Hughes, M. C. Raff, H. Thoenen, and M. Sendtner. 1991. Regional distribution, developmental changes, and cellular localization of CNTF-mRNA and protein in the rat brain. J. Cell Biol. 115:447-459.

2. Ernsberger, U., M. Sendtner, and H. Rohrer. 1989. Proliferation and differentiation of embryonic chick sympathetic neurons: effects of ciliary neurotrophic factor. Neuron. 2:1275-1284.

3. Louis, J-C., E. Magal, S. Takayama, and S. Varon. 1993. CNTF protection of oligodendrocytes against natural and tumor necrosis factor-induced death. Science (Wash. DC). 259:689-692.

4. Oppenheim, R. W., D. Prevette, Y. Qin-Wei, F. Collins, and J. MacDonald. 1991. Control of embryonic motoneuron survival in vivo by ciliary neurotrophic factor. Science (Wash. DC). 251:1616-1618.

5. Bazan, J. F. 1991. Neuropoietic cytokines in the hematopoietic fold. Neuron. 7:197-208.

6. Taga, T., and T. Kishimoto. 1992. Cytokine receptors and signal transduction. FASEB J. 6:3387-3396.

7. Stahl, N., S. Davis, V. Wong, T. Taga, T. Kishimoto, N. Y. Ip, and G. D. Yancopoulos. 1993. Cross-linking identifies leukemia inhibitory factor-binding protein as a ciliary neurotrophic factor receptor component. J. Biol. Chem. 268:7628-7631.

8. Ip, N. Y., J. McClain, N. X. Barrezueta, T. H. Aldrich, L. Pan, Y. Li, S. J. Wiegand, B. Friedman, S. Davis, and G. D. Yancopoulos. 1993. The $\alpha$ component of the CNTF receptor is required for signaling and defines potential CNTF targets in the adult and during development. Neuron. 10:89-102.

9. Davis, D., T. H. Aldrich, N. Y. Ip, N. Stahl, S. Scherer, T. Farruggella, P. S DiStefano, R. Curtis, N. Panayotatos, H. Gascan, et al. 1993. Released form of CNTF receptor a component as a soluble mediator of CNTF responses. Science (Wash. DC). 259:1736-1739.

10. Sendtner, M., H. Schmalbruch, K. A. Stockli, P. Carroll, G. W. Kreutzberg, and H. Thoenen. 1992. Ciliary neurotrophic factor prevents degeneration of motor neurons in mouse mutant progressive motor neuronopathy. Nature (Lond.). 358:502-504.

11. Ausubel, F. M., R. Brent, R. E. Kingston, D. D. Moore, J. G. Seidman, J. A. Smith, and K. Struhl. 1991. In Current Protocols in Molecular Biology. Wiley Intersciencem New York.

12. Henderson, J. T., N. A. Seniuk, and J. C. Roder. 1993. Localization of CNTF to neurons and astroglia in the CNS. Mol. Brain Res. In press.
13. Harlow, E., and D. Lane. 1988. Antibodies: A Laboratory Manual. Cold Spring Harbor Laboratory, Cold Spring Harbor, NY. 709 pp.

14. Gupta, S. K., M. Altares, R. Benoit, R. J. Riopelle, R. J. Dunn, and P. M Richardson. 1992. Preparation and biological properties of native and recombinant ciliary neurotrophic factor. J. Neurobiol. 23:481-490.

15. Aarden, L. A., M. P. Lansdorp, and E. R. DeGroot. 1985. A growth factor for B cell hybridomas produced by human monocytes. Lymphokines. 10:175185.

16. Metcalf, D., and D. P. Gearing. 1989. Fatal syndrome in mice engrafted with cells producing high levels of the leukemia inhibitory factor. Proc. Nat. Acad. Sci. USA. 86:5948-5952.

17. Rende, M., D. Muir, E. Ruoslahti, T. Hagg, and M. Manthorpe. 1992. Immunolocalization of ciliary neurotrophic factor in adult rat sciatic nerve. Glia. 5:25-32.

18. Deleted in proof.

19. Baumann, H., K. A. Won, and G. P. Jahreis. 1989. Human hepatocyte-stimulating factor III and interleukin-6 are structurally and immunologically distinct but regulate the production of the same acute phase plasma proteins. J. Biol. Chem. 264:8046-8051.

20. Schoolting, H., T. Stoyan, E. Roeb, P. C. Heinrich, and S. Rose-John. 1992. Ciliary neurotrophic factor induces acute-phase protein expression in hepatocytes. FEBS (Fed. Eur. Biochem. Soc.) Letters. 314:280-284.

21. Baumann, H., S. F. Ziegler, B. Mosley, K. K. Morella, S. Pajovic, and D. P. Gearing. 1993. Reconstitution of the response to leukemia inhibitory factor, oncostatin M, and ciliary neurotrophic factor in hepatoma cells. J. Biol. Chem. 268:8414-8417.

22. Kadekaro, M., J. Y. Summy-Long, S. Freemen, F. S. Harris, M. L. Terrell, and H. M. Eisenberg. 1992. Cerebral metabolic responses and vasopressin and oxytocin secretions during progressive water deprivation in rats. Am. J. Physiol. . 262:R310-317

23. Davis, S., T. H. Aldrich, D. M. Valenzuela, V. Wong, M. E. Furth, S. P. Squinto, and G. D. Yancopoulos. 1991. The $r$ ceptor for ciliary neurotrophic factor. Science (Wash. DC). 253:59-63.

24. Metcalf, D., N. A. Nicola, and D. P. Gearing. 1990. Effects of injected leukemia inhibitory factor on hematopoetic and other tissues in mice. Blood. 76:50-56.

25. Strassmann, G., M. Fong, J. S. Kennedy, and J. C. O. 1992. Evidence for the involvement of IL-6 in experimental cancer cachexia. J. Clin. Invest. 89:1681-1685.

26. Cheng, J., K. Turksen, Q. C. Yu, H. Schreiber, M. Teng, and E. Fuchs. 1992. Cachexia and graft-vs.-host-disease-type skin changes in keratin promoterdriven TNF alpha transgenic mice. Genes Dev. 6:1444-1456.

27. Ip, N. Y., Y. Li, I. Van De Stadt, N. Panayotatos, R. F. Alderson, and R. M. Lindsay. 1991. Ciliary neurotrophic factor enhances neuronal survival in embryonic rat hippocampal cultures. J. Neurosci. 11:3124-3134.

28. Ip, N. Y., S. H. Nye, T. G. Boulton, S. Davis, T. Taga, Y. Li, S. J. Birren, K. Yasukawa, T. Kishimoto, D. J. Anderson, et al. 1992. CNTF and LIF act on neuronal cells via shared signaling pathways that involve the IL-6 signal transducing receptor component gp 130. Cell. 69:1121-1132.27.

29. Hibi, M., M. Murakami, M. Saito, T. Hirono, T. Taga, and T. Kishimoto 1990. Molecular cloning and expression of an IL-6 signal transducer, gp 130. Cell. 63:1149-1157.

30. Clatterbuck, R. E., D. L. Price, and V. E. Koliatsos. 1993. Ciliary neurotrophic factor prevents retrograde neuronal death in the adult central nervous system. Proc. Natl. Acad. Sci. USA. 90:2222-2226.

31. Hagg, T., D. Quon, J. Higaki, and S. Varon. 1992. Ciliary neurotrophic factor prevents neuronal degeneration and promotes low affinity NGF receptor expression in the adult rat CNS. Neuron. 8:145-158.

32. Mackiewicz, A., T. Speroff, M. K. Ganapathi, and I. Kushner. 1991. Effects of cytokine combinations on acute phase protein production in two human hepatoma cell lines. J. Immunol. 146:3032-3037.

33. Wyngaarden, J. B., and L. H. Smith. 1988. In Cecil Textbook of Medicine. W. B. Saunders, Toronto, Ontario. 1315-1340.

34. Mori, M., K. Yamaguchi, S. Honda, K. Nagasaki, M. Ueda, O. Abe, and K. Abe. 1991. Cancer cachexia syndrome developed in nude mice bearing melanoma cells producing leukemia-inhibitory factor. Cancer Res. 51:6656-6659.

35. Beutler, G., J. Mahoney, N. Letrang, P. Pekala, and A. Cerami. 1985. Purification of cachectin, a lipoprotein lipase-suppressing hormone from endotoxin induced RAW-2647 cells. J. Exp. Med. 161:984-988. 